\title{
Leveraging on Video Technology for High-Leverage Practices
}

\author{
Leong Yew Hoong, Ho Foo Him \\ National Institute of Education, Nanyang Technological University, Singapore \\ Email: yewhoong.leong@nie.edu.sg
}

Received 2012

\begin{abstract}
In redesigning a methods course for Singapore Secondary Mathematics prospective teachers, we leverage on video technology to help them learn about the instructional practice of going through textbook-type questions. We find that this innovation generates learning all round - both for the student teachers as well as teacher educators.
\end{abstract}

Keywords: Mathematics Teacher Education; Video Technology; High-Leverage Practices

\section{Introduction}

In the effort to raise the quality of education in schools, teachers are seen to play a primary role in this enterprise. This focus on teachers turns the spotlight quite naturally to teacher education. One area that the spotlight shines upon is that of pre-service teacher education. There is growing interest, in particular, on the structure and contents of methods courses offered by Colleges of Education in Universities that can equip teachers adequately to enact quality instruction in the classrooms they subsequently work in.

Conventionally, the preparation of teachers for professional work follows the traditional theory-practice sequence: methods courses frontload student teachers with the knowledge about theories and principles of instruction; they then apply the knowledge acquired into practice during their teaching field placements (Darling-Hammond, 2010; Zeichner, 2010) However, in recent years, the basis of the model, with its sharp theory-practice divide, has been repeatedly questioned. It is argued that in the work of teaching, especially in the momentby-moment decision-making and improvisations in real-time classroom work, the practice of a teacher is not easily separable from the knowledge resources used by the teacher. For this reason, some scholars have coined hybrid terms to depict this view of teaching — such as a "thinking practice" (Lampert, 1998) or "knowtice" (Even, 2008), where knowledge and practice are combined into a single entity. Seen from this perspective, efforts to break teacher education components strictly into 'theory' and 'practice' components artificially distort the authentic work of teaching. Methods courses conducted under this traditional structure run the risk of being perceived by student teachers as being irrelevant to their 'real world' of teaching.

This call for a better understanding of the nature of teaching is sometimes misinterpreted as simply a movement to give student teachers more opportunities to enact practice during methods courses. However, a mere insertion of more practice sessions without paying careful attention to the tight relationship between knowledge and practice simply creates more cycles of theory-practice sequences in such courses. Thus, a redesign of a methods course involves a careful rethink about how relevant knowledge for teaching can be infused into student teachers' enactments of practice. In this paper, we focus on a redesigning in a methods course for prospective Secondary
Mathematics teachers.

\section{Units of Practice}

Lampert (2001) described the work of a teacher as a "complex activity” (p. 1). This view is shared by a number of education researchers (e.g., Chazan \& Ball, 1999; Stigler \& Hibert, 1999). The complexity is not unidimensional but on a number of 'planes': the social, temporal, and mathematics content planes. On the "social plane", a teacher must be aware that she interacts not only with one student but with a group of students, nested within bigger groups, extending to the whole class. While engaging with these different pockets of individuals, she has to be aware of the focus and direction of the whole class. On the "temporal plane", the work of teaching is not merely confined to a point in time, but is related to what goes on before and after, across units of time and across lessons extending to the whole year. On the "mathematics content plane", content is not comprised of disjoint pieces. They are related to each other logically and mathematically. Also, the complexity in the content often has to do with students accessing different content in a single problem context-for example, one student may be working on understanding the technical language of the problem, while another is solving the algebraic equations derived from the problem.

The complexity of the instructional task is accentuated by the need of the teacher to simultaneously weigh many factors in each decision during ongoing practice. She also does not have the luxury of a researcher-with time to analyse choices carefully - she has at most a few seconds. A teacher also has to juggle different and sometimes conflicting goals. She has to teach mathematics that matches the curriculum goals while inculcating a classroom environment where students do not merely take the teacher's word as the authority, but rather are able to reason using agreed-upon assumptions.

Given this picture of complexity, it seems reasonable, when considering the development of beginning teachers, not to present the complexities of teaching all at one-go. In other words, the practice of teaching has to be somewhat parsed into smaller units so that student teachers can start by learning about these components of practice without being overwhelmed by the overlapping complexities of overall practice (Lampert, 
2010).

The criteria for the selection of these units of practice for beginning teachers have been the source of much recent discussion in the literature on teacher education. Ball, Sleep, Boerst, and Bass (2009) used the term "high-leverage practices" for a set of core practices "in which the proficient enactment by a teacher is likely to lead to comparatively large advances in student learning" (p. 460, emphasis added). The primary focus in this conception of high-leverage practice is thus on its potential power in helping students learn mathematics if they are carried out as intended by the student teachers.

Using the same language of "high-leverage practices", Hatch and Grossman (2009) focused rather on such practices' proximity to actual teaching practices in regular classrooms and in its potential to generate opportunities of learning from practice: "[h]igh-leverage practices are approaches to teaching that can be used to address common problems of practice that teachers face and that novices will almost certainly need to employ once they begin teaching. High-leverage practices also enable novices to continue to learn” (pp. 76-77).

Approaching this matter from a different angle, Lampert, Beasley, Ghousseini, Kazemi, and Franke (2010) conceived of such practices in terms of its relative stability (with sufficient complexity to mirror actual practice and yet manageable for learning) and thus its suitability as a unit for rehearsal and analysis: "they are well-designed procedures that have been proven in practice, that take into account the complexity of goals that need to be accomplished, and that allow the practitioner temporarily to hold some things constant while working on others” (p. 130).

Thus, in selecting the type and size of basic units of practice for beginning teachers, we use a combination of criteria forwarded by the above writers: (1) it is a component of common practice that is readily useable (and adaptable) for their field placement; (2) it retains the need to deal with the complexity of balancing multiple instructional goals while having enough stable structure for proficiency through cycles of rehearsals; and (3) when carried out well in actual classroom settings, student learning takes place. One component of practice common in the Singapore mathematics classroom that fulfills these criteria is that of "going through textbook-type questions". For the rest of this paper, we focus solely on this particular unit of practice (henceforth known as the Practice).

\section{Leong Yew Hoong, Ho Foo Him}

"Going through" is a term that is commonly-used by Singapore mathematics teachers, as in "class, let's go through the homework questions", or "we go through the answers ...". Revising students (seat/home)work or teaching students how to tackle standard textbook-type questions is a regular and important part of the teacher's classroom work. This Practice presupposes the importance of students' regular practice of textbook-type questions as a way to gain fluency with mathematical procedures, representations, and language.

There is a perhaps a need to clarify at this juncture our stance on this Practice, especially in the context of widespread negative reaction towards 'drill-and-practise' in the western-based education community. We think that explicit teaching and student practice have a place in mathematics instruction in the schools. Its actual place is more clearly seen in the context of Schoenfeld's (1985) framework of mathematics problem solv- ing. There are four components in his framework: Cognitive resources, control, heuristics, and beliefs. It is in the area of cognitive resources that explicit step-by-step teaching finds its most prominent and useful place. Without fluency-through practice-with the mathematical skills and procedures, students will not have the most basic cognitive ingredients (such as arithmetic and algebraic manipulation dexterity) to attempt genuine mathematics problems. Thus, while explicit teaching of how to tackle standard questions cannot be all that is to mathematics teaching, we take the view that it has its place especially in fulfilling the goal of building cognitive resources in mathematics students.

However, because "going through questions" is so regularly done, many student teachers may wrongly assume that it is perfunctory work and thus lack preparations to do it well. In going through work with students, it is not merely about giving answers or telling them the right way to do it. Instead, it should be structured as a springboard to learn some mathematics content/processes that go beyond the boundary of the given question. It is thus a Practice that requires deliberate planning and rehearsal.

We think that when student teachers plan for this Practice, they should be led to see the direct relevance to their classroom mathematics teaching in future, address their own inadequacies in Subject Matter knowledge of mathematics, and connect the subject matter knowledge to active useable knowledge in their teaching. For these purposes, some relevant questions for student teachers to consider when planning to carry out this Practice include the list provided in Table $\mathbf{1 .}$

Apart from addressing the questions surrounding the Practice, it is important that student teachers, in the context of a mathematics methods course, be given the opportunity to demonstrate how these relevant strands of knowledge are put into the actual enactment of the Practice. However, instead of the traditional approach of asking student teachers to 'teach' (as in, within the mock setup of pretending their fellow student teachers are typical school students) during the methods course contact time, we think that the employment of videos is appropriate for this purpose. In other words, student teachers may, at times and venues convenient to them (and outside of the temporal and physical boundaries of the methods course time), video record their enactments of the Practice. They can then upload their videos to a designated site for submission and sharing among their course mates. We think that there are a number of benefits from this harnessing of video-related technology.

First, from the student teachers standpoint, they can review their initial recordings, perform (multiple) rehearsals before reaching a 'take' that they find satisfactory; in the process, they have the opportunity to reflect on the Practice and learn more about the knowledge required for the Practice (such as those reflected in the questions listed in Table 1). Second, for teacher educators conducting the methods course, we can preview these videos (through repeated playbacks, where necessary) before

Table 1.

Relevant questions for the Practice.

(a) How to do the question?

(b) How can the solution/reasoning/connections be presented more clearly in a visual representation on the whiteboard? 
(b) How can the solution/reasoning/connections be presented more clearly in a visual representation on the whiteboard?

selecting those that-when taken together-can help to highlight important emphases as feedback we want to give to the student teachers regarding the Practice. This pre-selection before contact-time can help to ensure that the course time is well-spent in discussing instructional issues that are directly relevant to them. Third, video-related technology is currently mature and stable enough not to pose significant technical hurdles that will render this initiative unworkable. For example, phones with video-recording function are ubiquitous in Singapore; as such, student teachers will find little difficulty taking suitably-high quality videos from these gadgets. The network infrastructure is also able to easily support the quick upload and stable storage of these videos.

\section{Method}

Given the setup of the Practice of "going through textbook-type questions" as was discussed in the earlier sections, we want to find out if and how an emphasis of such a Practice in a mathematics methods course for student teachers would help them learn relevant knowledge and craft skills about this practice, especially in the context of field placements subsequent to the completion of the course.

We introduced this Practice in the Secondary Mathematics methods course for all the student teachers enrolled in the January 2012 cohort of the Postgraduate Diploma in Education programme at the National Institute of Education-the sole teacher education institute in Singapore. We used the guiding questions listed in Table $\mathbf{1}$ to frame our lectures about the Practice, giving secondary-level mathematics textbook-type questions as examples for planning, enactments, and discussions during tutorial sessions. In total, about seven hours of course contact hours were used for this Practice.

As a follow-up, the student teachers were to complete a graded assignment based on this Practice. They were each assigned a different textbook-type question. The assignment required them to provide a written response to the guiding questions for the allocated problem; following that, they were to demonstrate the use of the knowledge about the Practice by video-recording how they enact the Practice for the given question. A particular video file format was prescribed to ensure uniformity in video quality; file-size limits were imposed to prevent under-capacity of server space and excessively long uploading times. Table 2 is an extract of the assignment instruction pertaining to the video upload.

As it turned out, all the student teachers in the course- ninety in total-were able to upload their files before the assignment deadline with little difficulty. After viewing the files, the respective tutors provided feedback to the student teachers based on selected snippets of the submitted videos, as planned. Subsequently, for the rest of the methods course, discussion about this Practice was carried out in the context of other assignments such as lesson planning and microteaching.

To study the usefulness of this Practice, the second author interviewed three selected student teachers-Avril, Suet Fang, and Jang Jung (all pseudonyms, and retaining their gender) - after they have completed their 10 -week field placements. The interviews were each about 10 minutes in duration. They centred round their thoughts about the Practice as it was em- phasised in the methods course and how it might (or might not) help in their field teaching.

The selection of the student teachers for interviews was based on a varied profile and also on the anticipated benefits that the Practice can provide them on certain specific aspects of their teaching craft and knowledge during field experience. Avril was among the most diligent student teachers in the methods course but-as seen from her performance during microteaching - was not able to fully translate the hard work in planning into quality actual teaching enactments. Jang Jung, too, did not perform well during the microteaching. Unlike Avril, he had a tendency to lose focus and become diffused when given the opportunity to practise explanation to his classmates as 'students'. Suet Fang, on the other hand, did quite well in microteaching but was noticeably not fully confident of the subject matter knowledge-possibly due to a non-mathematics specialisation in her undergraduate degree. Thus, in each interview, we had a different agenda; For Avril, it was to find out if the practice would sensitise her to certain craft skills that are needed for effective classroom delivery; for Jang Jung, the inquiry shifted to that of whether the Practice could help him focus better on a particular component of teaching - in this case, that of solving a textbook problem in class; as for Suet Fang, we meant to explore the potential of the Practice in deepening her subject matter knowledge-as reflected in the guiding question of learning beyond the content/process boundaries of textbook questions she taught during field experience.

Table 2.

Extract of assignment instruction.

Video record a 10-minute segment of your teaching to (imaginary) 'students' using the assigned question. [If there are 'students' involved in your segment, they are expected to give natural (that is, non-scripted) responses to your instructional moves]. In your segment, you are to incorporate the relevant ideas in your responses to [the guiding questions]. Details of how to prepare and submit the videos are as follows:

(a) Format and size of your video file

While the video recorder that you use may save the video file in a particular format, for the purpose of this assignment, you are to convert the file into the .xxx format. You may go to ... to download the convertor software to convert your video file to .xxx format. [Note that you may be prompted to install some requisite patches in the process]. The maximum file size for the .xxx video file that you can upload is 60MB. You are advised to view the file in this .xxx format prior to uploading to check that essential features of your video (such as clarity of working on the whiteboard, sound quality etc.) are not critically compromised.

(b) Upload of the .xxx video file

To upload the file, go to ...

You are advised against waiting till the very last few days to do the uploading. This is to provide ample time to sort out technical glitches, if any.

You are required to have a personal user id and password to upload your video file. Your user id is ... . The password is ...

Depending on your location and the level of internet connectivity, the upload may take up to 30 minutes. To check that you have successfully uploaded the file, you will be 
allowed to play the video after the upload. Re-submisson is allowed: you need to first delete the previous video you uploaded before doing a re-upload.

\section{Findings}

Based on the interview data, the responses of each of the interviewee is summarised as follows:

Avril: In recalling what she learnt from the Practice, she first pinpointed the feature of making eye contact as being important. She also mentioned that the opportunity to look at her own video enabled her to become more conscious of how she can improve, such as better visual representations and use of colours to highlight objects on the whiteboard for students. On "learn beyond", she admitted that she did not practise it regularly during field placement, attributing it to the students she taught- "weak even in grasping the standard questions". But she could recount one example where, after she used the $1 / 2 \mathrm{absinC}$ formula for area of triangle, she led students to see that it could also be solved using $1 / 2 \mathrm{bh}$, thus showing the connections. She added that her Cooperating Teacher (CT) "is very skillful" in extending the boundaries of questions by asking "what ifs" and proceeding not just to use, but also to prove theorems. [A Cooperating Teacher is a resident teacher of the placement school who is officially assigned to develop and grade the student teacher.] When asked if she thought that the Practice was useful during field experience, she answered that it was so "subconsciously", and emphasised that the Practice made her "aware", but there was still a need for regular rehearsals to sharpen its practice.

Suet Fang: Like Avril, she highlighted the video upload requirement of the assignment as the most useful part of the experience-stressing that the re-taking " $2-3$ " times allowed her to look at her whiteboard skills more carefully. She mentioned, in particular, that she spotted the following weaknesses from the videos: writings were too small, the lines were not straight, and the need to face the students. She found these realisations particularly useful in preparing her for field teaching. Like Avril, she did not consciously carry out the "learn beyond" in her field teaching, but she was able to recall one instance where she asked students to "go beyond" by "changing sizes" in the context of teaching mensuration. She asked them to do that as homework but didn't expect the typical students to be able to do it. She thought of this part as relevant only for "higher-order thinking”. Nevertheless, she thought the video upload for multiple re-takes/viewing was beneficial and should stay as an assignment for the methods course.

Jang Jung: He did three full-length takes for the video-recording but was still "not happy" with it, confessing that he was a "perfectionist". He learnt particularly about "facing the students"- -something that his CT pointed out to him again during field placement. He found the Practice "quite different" from field teaching because doing it with actual students in class required pausing at various junctures to ask questions to check for students' understanding-something he thought not required in the assignment. But he did point out the part of "having a good diagram drawn out" and "board spacing” when going through questions in class as being useful learning points for him. For the assignment, he suggested that instead of 'teaching' to an empty class or non-responding faces, some participants with pre-planned questions could help to check on the real-time reflexes of the teacher. With regard to "learn beyond", he tried to carry it out in the beginning but "toned down" later on. He pointed to one lesson where he taught the ambiguous case of the sine rule as "extension”. He was told by the CT that, for the students that he was teaching - judged to be weak academically - he should just focus on the usual examinable content.

Comparing the anticipated benefits we expect the Practice to offer for the respective student teachers (refer to the section above on reasons for selecting them for interviews) and the responses they gave during their interviews, there were matches as well as shortfalls. For Avril, she was made more aware of particular crafts of teaching - the eye contact and the whiteboard skills - and attempted to put them to practice during field teaching but felt that there was much more to do in this area; Jang Jung focused on "facing the students" and whiteboard skills as key takeaways that he found applicable during field teaching, but realized that actual classroom instruction was substantially more complex than video-recording for the Practice; Suet Fang did a little on "learn beyond" but there was no evidence to indicate that she did more to challenge her levels of subject matter knowledge.

\section{Discussion and Conclusion}

Although the responses of Avril, Suet Fang, and Jang Jung were varied, there are some discernible underlying commonalities. First, with regard to the video upload requirement of the assignment, they found the opportunity to re-take and review useful in helping them identify specific weaknesses in their teaching craft. In particular, all of them pointed to the way they presented their workings/diagrams on board as one area of attention. This is in line with the emphasis of guiding question (b) (see Table 1) of this Practice on the use of visual representations on the whiteboard. Second, each of them found some relevance of this Practice to their teaching during their field experiences. For Avril, it was the exposure to the "learn beyond" part of the Practice that made her "aware" of how her CT was practising it "skillfully"; for both Suet Fang and Jang Jung, the Practice revealed the importance of facing the class and attending to students' needs-aspects they found useful for their teaching during field placement. Third, all of them supported the keeping of this assignment as an important part of the methods course for future cohorts of the same programme.

There are, however, significant disjunctions too. With respect to the part of "learn beyond" in the Practice, Suet Fang seemed not to think that it was relevant, especially for 'weaker' students; Avril saw it as a good for the students-as evidenced from how she saw her CT as being "skillful" in it, and by implication, something worth emulating-but a skill she was perhaps not yet adept at due to insufficient practice. Nevertheless, the mention of her students bring "weak in grasping standard questions” revealed her implicit agreement with Suet Fang that it was more suitable for students deemed 'stronger' in mathematics; As for Jang Jung, it was not clear what his belief about "learn beyond" was. But it was clear that he was initially sufficiently convinced of its importance to carry it out in the first part of his field teaching, only to "tone down" when told by his CT that he should focus on standard questions.

In any case, their (or their CTs') conceptions of "learn beyond" as something meant only for the 'mathematically-strong' or being about extending far beyond examinable content were quite different from how we conceive this part of 
the Practice. To us, "learn beyond" is about not stopping at merely completing the solution of a textbook question; rather, the teacher should lead students to think-habitually-about how the method or solution in tackling that particular question helps students to learn something that they do not previously know about. Clearly, this conception that we have of "learn beyond" is not meant only for the "higher order" thinkers, nor does it detract from the focus on examinable content.

In summary, from this exploratory study, we are encouraged by the overall operational smoothness and generally positive student teachers' sentiments with regard to the video upload assignment as part of the methods course. However, from the point-of-view of it being a "high-leverage" practice as advanced by the reviewed literature, our proposed Practice of "going through textbook-type questions" requires some refinements. First, there is a need to close the perceived gap between what student teachers do in the Practice and what they actually experience in the classroom during field placements. Jang Jung, in particular, pointed out that the absence of authentic student responses during the enactment of the Practice rendered it somewhat distant from actual teaching practice. This potentially compromises the readily-useable criterion of high-leverage practices reviewed earlier. On the other hand, if we take Jang Jung's suggestion-to plant some 'students' in to create some authenticity-we run into the other danger of over-complexifying the Practice to the point that it violates the other principle of sufficiently-stable structure for focused examination and rehearsal. We suggest that a balance point may be found by adding these requirements to the existing assignment: there must be an audience, and you must include questions at suitable junctures in your enactment of the Practice.

Also, there is a need to make clearer in the methods course what we intend "learn beyond" to mean and to look like during the Practice. To us, it is important for student teachers to go beyond solving a textbook question for students; they need to make explicit to students what connections/knowledge/process they intend to foreground to students when they select particular textbook questions to solve with the class. However, the way the current related question (c) (see Table 1) is phrased might not have conveyed this flavour clearly to the student teachers. Instead, we may put it in a way that 'forces' them to articulate the "beyond this question" purpose, such as, "As a teacher, you are interested not only in teaching your students the way to solve THIS question. Surely, you choose to 'go through' this question in order to highlight something worthwhile for students to learn. State clearly what they are and demonstrate it explicitly in your video enactment”.

As teacher educators, this study has been useful both in testing video technology for our methods course and in helping us refine the conception of Practice that will help our student teachers develop high-leverage practices. Our next step in further research will proceed along the refinements proposed for the subsequent methods course, and, beyond that, to consider other Practices that can be incorporated in the pre-service programme.

\section{REFERENCES}

Ball, D. L., Sleep, L., Boerst, T., \& Bass, H. (2009). Combining the development of practice and the practice of development in teacher education. Elementary School Journal, 109(5), 458-474.
Chazan, D., \& Ball, D. L. (1999). Beyond being told not to tell. For the Learning of Mathematics, 19(2), 2-10.

Darling-Hammond, L. (2010). Teacher education and the American future. Journal of Teacher Education, 61(1-2), 35-47.

Even, R. (2008). Making sense of students' talk and action for teaching mathematics. A regular lecture given at the 11th International Congress of Mathematics Education at Monterrey, Mexico. Retrieved from

http://stwww.weizmann.ac.il/menu/personal/ruhama_even/index.htm l on $8 \mathrm{Feb} 2011$.

Hatch, T., \& Grossman, P. (2009). Learning to look beyond the boundaries of representation: Using technology to examine teaching (Overview for a digital exhibition: Learning from the practice of teaching). Journal of Teacher Education, 60(1), 70-85.

Lampert, M. (1998). Studying teaching as a thinking practice. In J. Greeno \& S.G. Goldman (Eds.), Thinking Practices. Hillsdale, NJ: Lawrence Erlbaum and Associates.

Lampert, M. (2001). Teaching problems and the problems of teaching. New Haven, CT: Yale University Press.

Lampert, M. (2010). Learning teaching in, from, and for practice: What do we mean? Journal of Teacher Education, 61(1-2), 21-34.

Lampert, M., Beasley, H., Ghousseini, H., Kazemi, E., \& Franke, M. (2010). Using designed instructional activities to enable novices to manage ambitious mathematics teaching. In M. S. Stein \& L. Kucan (Eds.), Instructional explanations in the disciplines (pp. 129-141). Springer: NY.

Schoenfeld, A. (1985). Mathematical problem solving. Orlando, FL: Academic Press.

Stigler, J. W. \& Hiebert, J. (1999). The teaching gap. Best ideas from the world's teachers for improving education in the classroom. New York: Free Press.

Ball, D. L., Sleep, L., Boerst, T., \& Bass, H. (2009). Combining the development of practice and the practice of development in teacher education. Elementary School Journal, 109(5), 458-474.

Chazan, D., \& Ball, D. L. (1999). Beyond being told not to tell. For the Learning of Mathematics, 19(2), 2-10.

Darling-Hammond, L. (2010). Teacher education and the American future. Journal of Teacher Education, 61(1-2), 35-47.

Even, R. (2008). Making sense of students' talk and action for teaching mathematics. A regular lecture given at the 11th International Congress of Mathematics Education at Monterrey, Mexico. Retrieved from

http://stwww.weizmann.ac.il/menu/personal/ruhama_even/index.htm l on $8 \mathrm{Feb} 2011$.

Hatch, T., \& Grossman, P. (2009). Learning to look beyond the boundaries of representation: Using technology to examine teaching (Overview for a digital exhibition: Learning from the practice of teaching). Journal of Teacher Education, 60(1), 70-85.

Lampert, M. (1998). Studying teaching as a thinking practice. In J. Greeno \& S.G. Goldman (Eds.), Thinking Practices. Hillsdale, NJ: Lawrence Erlbaum and Associates.

Lampert, M. (2001). Teaching problems and the problems of teaching. New Haven, CT: Yale University Press.

Lampert, M. (2010). Learning teaching in, from, and for practice: What do we mean? Journal of Teacher Education, 61(1-2), 21-34.

Lampert, M., Beasley, H., Ghousseini, H., Kazemi, E., \& Franke, M. (2010). Using designed instructional activities to enable novices to manage ambitious mathematics teaching. In M. S. Stein \& L. Kucan (Eds.), Instructional explanations in the disciplines (pp. 129-141). Springer: NY.

Schoenfeld, A. (1985). Mathematical problem solving. Orlando, FL: Academic Press.

Stigler, J. W. \& Hiebert, J. (1999). The teaching gap. Best ideas from the world's teachers for improving education in the classroom. New York: Free Press. 